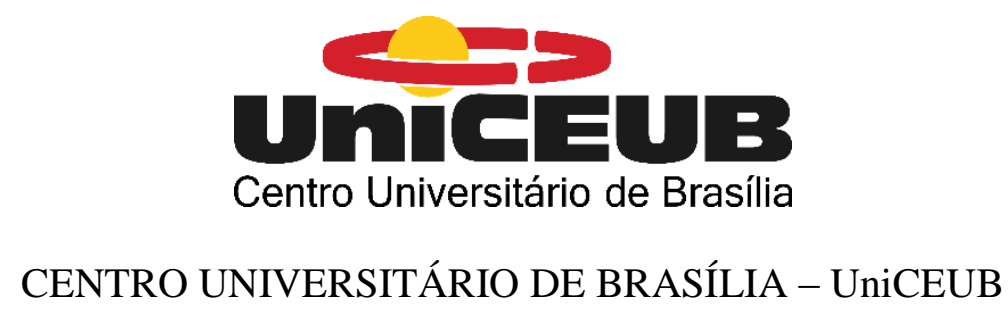

PROGRAMA DE INICIAÇÃO CIENTÍFICA

MATHEUS COSTA FRANÇA

VOZES ANTIFEMINISTAS NAS REDES SOCIAIS - UMA ANÁLISE DE CONTEÚDO

BRASÍLIA 


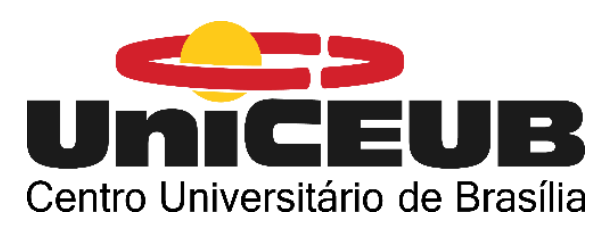

MATHEUS COSTA FRANÇA

VOZES ANTIFEMINISTAS NAS REDES SOCIAIS - UMA ANÁLISE DE CONTEÚDO

Relatório final de pesquisa de Iniciação Científica

Apresentado à Assessoria de Pós-Graduação e Pesquisa.

Orientação: Profa. Dra. Marcia Guedes Vieira

Brasília 


\title{
Vozes antifeministas nas redes sociais - Uma análise de conteúdo
}

\section{Matheus Costa França}

matheuscfs97@sempreceub.com

\section{Profa. Dra. Marcia Guedes Vieira}

marcia.guedes.vieira@gmail.com

\author{
Profa. Dra. Ana Lúcia Figueiró \\ ana.figueiro@ceub.edu.br
}

Esta pesquisa buscou mapear conteúdos antifeministas elaborado por mulheres e disponibilizados em redes sociais, blogs, sites, canais do Youtube e estabelecer uma comparação com os conteúdos e fundamentos teóricos feministas, a fim de compreender quais os principais pontos de oposição ao feminismo, seus argumentos e se o conteúdo antifeminista demonstra compreensão dos conceitos aos quais está combatendo. O papel da mulher na sociedade vem sofrendo profundas mudanças em diversas culturas ao redor do globo. $\mathrm{O}$ movimento feminista desempenha um papel fundamental em tais mudanças. No Brasil, o movimento vem ganhando força nos últimos anos, e a internet tem sido um instrumento importante para a divulgação e o compartilhamento de opiniões e ideias. Em oposição ao movimento feminista, o movimento antifeminista também ganhou voz e utiliza o espaço cibernético, com páginas, blogs e canais virtuais para disseminar seu discurso. As refutações ao feminismo encontram fundamento nas relações sociais, materiais e de produção ancoradas no pensamento patriarcal e senhorial que definiu as relações sociais e de poder no Brasil. Adotou-se a perspectiva de pesquisa qualitativa, do tipo exploratória. O método utilizado foi o de análise de conteúdo, abordando a técnica temática-categorial. O objeto de estudo foi constituído por três fontes escolhidas para análise. A primeira fonte foi constituída pela fundamentação teórica do feminismo na bibliografia adotada. A segunda foi formada pelos grupos posicionados a favor do movimento feminista nas redes sociais. A terceira foi composta pelos grupos posicionados contra o movimento feminista nas redes sociais. A utilização do método de análise de conteúdo possibilitou perceber a grande discrepância de opiniões das duas agendas, assim como a clara disseminação de discursos de ódio e de informações sem fundamentação teórica do discurso antifeminista. Foi possível observar que as páginas antifeministas no Facebook têm menos seguidores comparadas aos blogs e páginas 
relacionados aos movimentos feministas, além disso as páginas antifeministas não conseguem se manter no ar por muito tempo e sofrem críticas sistemáticas de feministas e de páginas feministas conscientizadoras.

Palavras-Chave: Feminismo. Antifeminismo. Redes Sociais. Ativismo Digital. 


\section{AGRADECIMENTOS}

Ao UniCEUB, seu corpo docente e à Assessoria de Pós-Graduação e Pesquisa da instituição, por esta oportunidade de iniciação científica que tanto contribuiu para o meu conhecimento.

A aluna Carolina Campos Vidotto, por dar início a este projeto e idealizar esta pesquisa, e por confiar no meu potencial para continuá-la.

A minha orientadora Márcia Guedes Vieira, pela minha indicação para dar continuidade à esta pesquisa, pela confiança no meu potencial, e principalmente pela orientação tão cuidadosa, além do incentivo quando a pesquisa se dificultava e eu me encontrava em dúvida.

A colaboradora Ana Lúcia Figueiró, por se disponibilizar generosamente durante a reta final da pesquisa, onde encontramos maior dificuldade e problemas externos.

Aos meus pais e amigos pelo incentivo e apoio incondicional.

E a todos que direta ou indiretamente fizeram parte deste processo de produção de conhecimento. 


\section{SUMÁRIO}

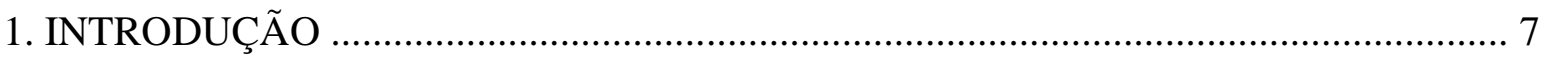

2. FUNDAMENTAÇÃO TEÓRICA …............................................... 9

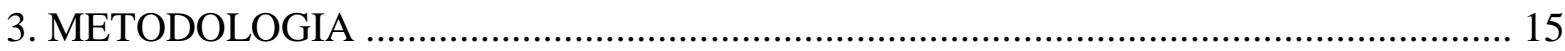

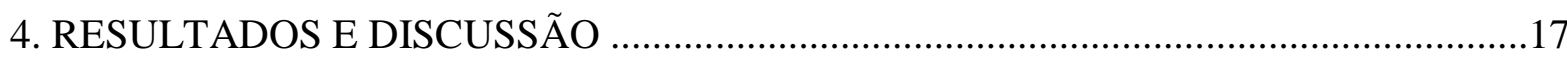

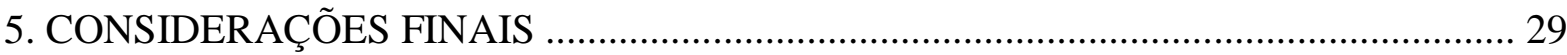

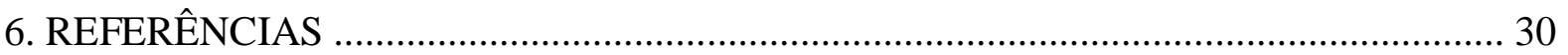




\section{Introdução}

O papel da mulher na sociedade vem sofrendo profundas mudanças em diversas culturas ao redor do globo. Mudanças que se deram a partir de manifestações femininas motivadas pela oposição ao regime machista opressor de sociedades patriarcais. As reivindicações das mulheres permeiam a história desde muito antes do reconhecimento histórico do movimento feminista, caracterizado pelo movimento sufragista nos Estados Unidos (CASTELLS, 2001).

Para Franco Restaino (apud CACACE, 2006), o movimento feminista nasceu oficialmente a partir da publicação, em 1792, do livro de Mary Wollstonecraft, "Uma reivindicação pelos direitos da mulher". Mas, se considera como a primeira onda do feminismo o período de 1848 a 1918, por ter tido implicações mais amplas e significativas para as mulheres.

$\mathrm{Na}$ atualidade, o reconhecimento do movimento feminista disseminou a rápida e irreversível conscientização da necessidade de redefinição da identidade da mulher, combatendo a determinação do poder a partir das diferenças de sexo. Assim, podemos dizer que o feminismo se revela "em todas as esferas em que mulheres buscam recriar as relações interpessoais sob o prisma onde o feminino não seja o menos, o desvalorizado" (ALVES; PITANGUY, 1985, p. 09). As implicações das lutas feministas incluem, ao longo de lutas históricas, os mais diversos frutos como "o direito da mulher ao voto, a criação dos métodos contraceptivos, as leis de proteção contra a violência à mulher (como a Lei Maria da Penha no Brasil), a licença maternidade e outros direitos trabalhistas" (LANGNER; ZULIANI; MENDONÇA, 2015, p. 04).

No Brasil, o tema da violência contra a mulher no próprio lar, colocado em pauta pelo movimento feminista ganha impulso ainda no período da ditadura militar, na década de 1970, no contexto das demandas pela anistia política de homens e mulheres, vítimas da violência militar. Várias estratégias de luta política foram implementadas, levando a conquistas legislativas, jurídicas e institucionais (BANDEIRA 2009).

Atualmente, as tecnologias de informação e comunicação se tornaram palco de fortalecimento da luta feminista, em um fenômeno denominado de ativismo digital. A apropriação das plataformas digitais encaminhou o feminismo a uma trajetória com "maior visibilidade, disseminação de ideias, aderência de novos adeptos, além de possibilitar uma contra resposta às veiculações consideradas machistas, acarretando, por fim, em conquistas concretas aos movimentos" (LANGNER; ZULIANI; MENDONÇA, 2015, p.13). 
Por outro lado, a crítica antifeminista no Brasil ganha força com a depreciação e a deslegitimação do feminismo que, segundo Schmidt (2006) está presente no cotidiano popular - alimentado pelo senso comum -, na esfera pública de produção e circulação de bens culturais e na área acadêmica que, segundo a autora

é onde também se dissemina em discursos reducionistas, de conotação pejorativa e preconceituosa. Vulgarizar o feminismo e associá-lo às noções de marginalidade e anacronismo para marcar a natureza de algo que não é bom, sadio e desejável para a sociedade brasileira (SCHMIDT, 2006, p.766).

A constante evolução da internet, possibilitou que seus usuários se conectassem em comunidades, que os permitiu consumir e disseminar conteúdos de uma forma nunca vista antes.

Um mundo virtual, no sentido amplo, é um universo de possíveis, calculáveis a partir de um modelo digital. Ao interagir com o mundo virtual, os usuários o exploram e o atualizam simultaneamente. Quando as interações podem enriquecer ou modificar o modelo, o mundo virtual torna-se um vetor de inteligência e criação coletivas. (LEVY, 1999 p.75).

Ao transitar por sites, blogs, canais do Youtube e páginas no Facebook é possível observar que o discurso antifeminista em redes sociais busca sustentar seus argumentos com a divulgação de condutas supostamente antiéticas e até criminosas de mulheres, como por exemplo: "Menina de 15 anos que disse ter sido estuprada mentiu para se encontrar com namorado...", ou "Padrasto fica preso mesmo após enteada dizer que inventou estupro. Mecânico foi denunciado em 2009...”; "Mulher que matou gestante para não terminar com namorado é presa!"1. Há também afirmações do tipo: "Somos contra: o sexismo feminista; a negação das diferenças naturais entre os gêneros; as falsas acusações de estupro,etc. Somos a favor: da igualdade perante a lei; da liberdade de expressão,etc"2 ${ }^{2}$ O conteúdo busca, aparentemente, pautar a existência desse tipo de posicionamento apenas para contrapor-se às ideias feministas.

Esta pesquisa buscou mapear conteúdos antifeministas disponibilizados nas redes sociais à luz dos conceitos produzidos pelo movimento feminista, a fim de identificar a existência de um ativismo digital antifeminista promovido principalmente por mulheres e estabelecer uma comparação com os conteúdos e fundamentos teóricos feministas. A ideia foi fazer um

\footnotetext{
${ }^{1}$ http://www.antifeminismo.com.br/ Acesso em 01/05/2017

${ }^{2}$ https://www.facebook.com/resistencia.anti.feminismo.marxista/ Acesso em 01/05/2017
} 
paralelo dos conteúdos a fim de compreender quais os principais pontos de oposição ao feminismo, seus argumentos e se o conteúdo antifeminista demonstra compreensão dos conceitos aos quais está combatendo. Além disso, o estudo se preocupou em observar se os conteúdos antifeministas estimulam uma cultura do estupro ou são produtores de misoginia, e, identificar o perfil do público produtor e seguidor desses espaços.

Sobre o processo da pesquisa, é importante informar que ocorreu uma troca de pesquisador devido à saída da aluna pesquisadora e idealizadora do projeto. Isso ocorreu logo ao fim do semestre letivo 2-2017. A solução encontrada foi a substituição da pesquisadora por outro aluno do curso de Psicologia que teve interesse no tema. Essa troca de pesquisador gerou um atraso no cronograma, pois o novo aluno teve que se apropriar do que já estava em andamento, e, principalmente, ler todo o material bibliográfico selecionado até aquele momento. Entretanto, no nosso entender, isso não prejudicou o andamento do estudo.

\section{Fundamentação Teórica}

Segundo Castells (2001, p. 210), o movimento feminista é a consequência do poder da congregação feminina. $\mathrm{O}$ autor trata o movimento como um fenômeno rico e variado, que adquire múltiplos contornos ao ser analisado pela perspectiva global.

Existe, portanto, uma essência comum subjacente à diversidade do feminismo: o esforço histórico, individual ou coletivo, formal ou informal, no sentido de redefinir o gênero feminino em oposição direta ao patriarcalismo. (CASTELLS, 2001, p.211)

Com a popularização da internet nos anos 90, o feminismo se apropriou das redes como uma nova ferramenta favorável à participação das mulheres na tecnologia, um fenômeno que ganhou o nome de ciberativismo

$\mathrm{Na}$ relação entre feminismos, tecnologia e internet esses grupos apostaram no potencial transformador dessa articulação, no que diz respeito à apropriação de novas tecnologias, nos seus processos mais horizontais de funcionamento, nos novos espaços a serem ocupados (a internet entendida como um desses lócus por excelência) e na desconstrução de categorias pré-fixadas e unitárias do binarismo de gênero. (FERREIRA, 2015, p. 44).

Ao longo dos anos, importantes movimentos feministas utilizaram-se das redes sociais para promover o ativismo digital mundialmente. A Marcha Mundial das Mulheres, organizada nos anos 2000, e a Marcha das Vadias, em 2011 utilizaram-se de blogs e redes sociais para 
promover a divulgação e adesão às marchas, tanto como para o combate ao machismo e qualquer forma de violência contra a mulher. Em 2014, a atriz Emma Watson, na condição de embaixadora da boa vontade da Organização das Nações Unidas Mulheres, promoveu a campanha \#HeforShe, que se tornou viral de forma imediata, sendo rapidamente aderida por artistas mundialmente conhecidos. As ideias difundidas pela campanha incluíam o chamado para que os homens também aderissem à luta do feminismo; o esclarecimento de que o feminismo não é um movimento de ódio aos homens e sim uma luta pela igualdade de gênero; que mulheres devem ter o direito sobre o próprio corpo; a mulher deve ter papel ativo na criação de suas próprias políticas públicas (LANGNER; ZULIANI; MENDONÇA, 2015).

A internet é um espaço aberto a todas a ideias, tanto que de acordo com Castells (apud SOUSA; FRANCHINI; NASCIMENTO, 2016, p. 05), há um receio na sociedade de que um poder ou um sistema não represente seus ideais, seus sentimentos e a internet possibilita a ruptura de um ciclo de dominação e viabiliza a manifestação de ideias e pensamentos que podem ter significado "para indivíduos igualmente insatisfeitos que irão se apropriar da mensagem disseminando-a através de seus nós de compartilhamento, pois a internet, a princípio é um espaço protegido, rápido e que não pode ser reprimido”.

Nesse sentido, a internet e as redes sociais viabilizam a criação do indivíduo virtual, que produz e consome informação (SOUSA; FRANCHINI; NASCIMENTO, 2016) formando redes de debates de determinadas ideias, e assim, torna possível a tomada de posições políticas e a expressão de valores éticos e morais aparentemente de forma mais segura, e com a ideia de anonimato. Deste modo, o ambiente virtual viabiliza a veiculação e tomada de posições que vão contra ideias feministas de forma mais segura, sem levar a um embate público. No que diz respeito às opiniões ao feminismo, a internet pode fortalecer o movimento, ou o caminho inverso, pois "Desse modo, a internet pode representar uma libertação do discurso feminista, mas também pode ser utilizada para o fortalecimento do machismo na sociedade” (RODRIGUES, GADENZ e LA RUE, 2014, p. 17)

Segundo Medina (2014, p. 72), após um trabalho de pesquisa e análise do blog Testosterona, a autora conclui que "foi possível perceber o quanto o machismo ainda é presente em nossa sociedade, herança de séculos de dominação patriarcal”. Esse fato é muito bem representado nas postagens do blog citado, que promove o machismo, a misoginia, a visão de que o sexo feminino é inimigo do sexo masculino. 
Como resultado de uma longa herança cultural guiada pelo patriarcado, o machismo ainda é uma mentalidade instalada em várias esferas da cultura brasileira, sendo refletido também nos conteúdos que preenchem as redes sociais

No caso do movimento feminista, vê-se que, nas últimas décadas, apesar de ter conquistado a ampliação dos direitos da mulher, com ações fundamentais na luta pela igualdade de gêneros, a igualdade entre homem e mulher ainda não é plenamente garantida na sociedade, que segue marcada por traços machistas característicos da cultura do patriarcado (RODRIGUES, GADENZ e LA RUE, 2014, p. 25).

Lutar pela equidade entre homens e mulheres é uma demanda constante da agenda feminista, nutrida pela recorrente desvalorização e submissão da figura feminina perante a sociedade. As desigualdades foram fundamentadas nas diferenças biológicas entre homens e mulheres, ganhando raízes tão profundas que essas ideias se fixaram na esfera cultural, permeada entre gerações. Alves \& Pitanguy (1985, p. 54-55) destacam que o feminismo

Questiona assim a ideia de que homens e mulheres estariam predeterminados, por sua própria natureza, a cumprir papéis opostos na sociedade: ao homem, o mundo externo, à mulher, por sua função procriadora, o mundo interno. Essa diferenciação de papéis na verdade mascara uma hierarquia, que delega ao homem a posição de mando.

Alves \& Pitanguy (1985, p. 55-56) citam Simone de Beauvoir, que afirma em sua obra O segundo sexo, que “o 'masculino' e 'feminino' são criações culturais" e "comportamentos aprendidos". Essas definições culturais têm a função de naturalizar a relação de poder entre os sexos e estabelecer quais comportamentos são adequados para cada gênero. $\mathrm{O}$ reducionismo biológico então se torna um alvo de críticas do movimento feminista, e incentiva a formulação de uma nova mentalidade acerca das atribuições de gênero.

O termo empoderamento se refere à luta de grupos que desafiam a relação de poder. De uma forma ampla, a definição do empoderamento feminino está associado à oposição à ideologia do poder patriarcal. Prega a reforma de estruturas e instituições que fortalecem a discriminação de gênero e a desigualdade social. As estruturas e instituições citadas por Batliwala (1994, p. 130) englobam a família, religião, a mídia, sistemas de saúde e educação, leis e códigos civis, processos políticos, instituições governamentais, entre outros.

Segundo Castells (2001, p. 170), a incorporação da mulher no mercado de trabalho aumentou seu poder na sociedade, abalando a dominação masculina como único provedor familiar, ao mesmo tempo que o trabalho remunerado aumentou a jornada da mulher, tendo que também 
cuidar da casa, dos filhos e da jornada noturna de atendimento às necessidades do marido. Deste modo, a contestação ao modelo de família patriarcal, que sustenta o patriarcalismo, foi ganhando força, impulsionada por esses processos, e também pelo avanço de uma economia informacional global e também de tecnologias relacionadas ao processo de reprodução humana. "Primeiro os anticoncepcionais, depois a fertilização in vitro e a manipulação genética [...] são fatores que permitem à mulher e à sociedade controle cada vez maior sobre a ocasião e a frequência das gestações”.

A organização das mulheres em todo o mundo nos últimos 40 anos tem transformado o cenário da luta política em diferentes países e de forma e intensidade diferenciadas, dependendo da conjuntura e da cultura de cada país. Mas, como bem ressalta Castells (2001, p. 171) "essa não é e nem será uma revolução de veludo. A paisagem humana da liberação feminina está coalhada de cadáveres de vidas partidas, como acontece em todas as verdadeiras revoluções". Apesar disso, a mobilização das mulheres tem trazido "consequências fundamentais para a experiência humana, desde o poder político até a estrutura da personalidade".

Tal capacidade de abalar estruturas de poder, ou de pelo menos levantar a bandeira da possibilidade de derrubada do poder patriarcal, só poderia gerar tamanha contestação e violência contra as mulheres e ao movimento feminista.

A Organização das Nações Unidas Mulheres reconhece o empoderamento das mulheres como um sinônimo de desenvolvimento. Para nutrir esse desenvolvimento, a ONU Mulheres e o Pacto Global criaram os Princípios de Empoderamento das Mulheres. São sete princípios que incluem a promoção da igualdade de gênero; oportunidades iguais, inclusão e nãodiscriminação; saúde, segurança e fim da violência; educação e formação; desenvolvimento empresarial e práticas da cadeia de fornecedores e de marketing; liderança e engajamento comunitário; transparência, medição e relatórios.

Empoderar mulheres e promover a equidade de gênero em todas as atividades sociais e da economia são garantias para o efetivo fortalecimento das economias, o impulsionamento dos negócios, a melhoria da qualidade de vida de mulheres, homens e crianças, e para o desenvolvimento sustentável (ONU Mulheres) ${ }^{3}$.

A violência no Brasil atinge predominantemente os homens, sendo estes envolvidos tanto como vítimas quanto como agressores, segundo dados registrados no sistema de informação

\footnotetext{
${ }^{3}$ http://www.onumulheres.org.br/referencias/principios-de-empoderamento-das-mulheres/
} 
da saúde, da segurança pública e da justiça. Este fato reforça o que Leila Garcia (2016) denomina de "magnitude invisível da violência contra a mulher". Essa forma de violência é, em sua maioria, dotada de características próprias, uma vez que predominantemente ocorrem no âmbito privado, e cometida por familiares e conhecidos. Devido a tais peculiaridades, essas "ocorrências não geram atendimentos e não são captadas pelos sistemas de informação, o que resulta em subenumeração dos eventos, e contribui para reforçar a invisibilidade da violência contra a mulher" (GARCIA, 2016, p. 451).

Desse modo, a violência contra a mulher só vem a ganhar evidência quando ocorrem casos extremos que ganham grande repercussão na mídia e em redes sociais, como estupros coletivos e casos de feminicídio, um crime tipificado pela Lei 3.104/2015, que entrou em vigor em março de 2015 (GARCIA, 2016). De acordo com a nova Lei, passa a ser homicídio qualificado a morte de mulher por razões de sexo feminino.

Os temas supracitados são pautas atuais do movimento feminista, tornando-se assuntos de discussão inclusive pelos ciberativistas. Contudo, como visto em estudos anteriores, a luta não passa ilesa pelo confronto machista e difamador, que permanece vivo nos discursos online.

O cenário virtual, ou o ciberespaço, passa a se constituir em importante território da esfera social, a ágora eletrônica contemporânea, que possibilita dar visibilidade aos fatos da vida privada, tratar fatos e fenômenos da esfera pública e sobretudo redimensionar a esfera social. (VELLOSO, 2011, p.108)

Uma questão inicial que suscitou a ideia dessa pesquisa foi o que leva mulheres a se intitularem antifeministas, e a se organizarem no espaço virtual por meio de páginas no Facebook, blogs, sites e canais do Youtube para combater os movimentos feministas. Embora a pesquisa não tenha levantado o nível etário dessas mulheres, percebeu-se a grande presença de mulheres jovens protagonizando e defendendo a bandeira antifeminista. Encontramos em Cacace (2006) uma possível explicação, ou pelo menos uma aproximação de um entendimento sobre a dificuldade de adesão de uma parcela jovem aos ideários feministas. Segundo a autora, a transição da modernidade para a pós-modernidade está relacionada a processos de fragmentação e diferenciação que afetam tanto a vida social, como a econômica e a política.

En la vertiente social, se asiste a la diferenciación de los estilos de vida, de los modelos de comportamiento y de las representaciones de la realidad, pero también a la debilitación de los sistemas de estatus y 
roles y a la consiguiente fragmentación de las identidades individuales.

En la vertiente económica, la sociedad postmoderna se caracteriza por la [..] fragmentación del mercado de trabajo y por las redes de las estructuras de producción.

Finalmente en la vertiente política hay visibles procesos que llevan a perder su centralidad a las estructuras políticas estatales, a la difusión de los centros de poder autónomos y de iniciativa política, y a las crisis de las formas tradicionales de asociacionismo político y sindical (CACACE, 2006, p. 33)

Assim, ao discutir a dificuldade de identificação de mulheres jovens ao feminismo, a autora se refere a essas mulheres como portadoras de uma sensibilidade pós-moderna. Ao analisar uma pesquisa com jovens mulheres, Cacace (2006, p. 41) sugere que algumas delas não conseguem imaginar um sujeito feminista unitário.

La mayoría de las jóvenes, aun cuando experimenten problemas comunes, parece que no pueden ni quieren salir de la dimensión individual de su propia originalisima, estratificada, compleja identidad para ponerse en relación con las otras y con una historia común como mujer. Cada cual pone así al descubierto, a través de su propia vida, una "micro-narración" personal.

A expansão de uma perspectiva individualista e que valoriza a fragmentação e diferenciação pode, então, ter um reflexo na conduta política e ideológica de mulheres antifeministas. Segundo Harvey (1994), a perspectiva de pós-modernidade entende o mundo e tudo o que ocorre nele como efêmero, fragmentário e descontínuo. Por isso, não aceita metanarrativas, e verdades "universais", como reação a uma ideia de modernidade que aceita a possibilidade de haver um único modo de apreender e representar o mundo, de maneira racional, organizada e controlada.

Segundo Amelia Valcárcel (2016, p. 201) esse movimento inverso às lutas feministas não é novo. A autora lembra que as mulheres dos anos 50, do século $\mathrm{XX}$, foram muito menos militantes que suas mães, a geração das sufragistas. Estas mulheres viram suas filhas reproduzirem papéis tradicionais, com ideias retrógradas, “embujadas que no querían disponer de sus nuevos poderes y a quienes sus madres parecían, con sus críticas constantes a su modo de vida, viejas brujas". Entretanto, essas mulheres tradicionais geraram a geração dos anos 70, "cuyo nivel de intelección y compromiso, de propuesta, y capacidad de difusión fue formidable. 
A análise de Amelia Valcárcel traz uma perspectiva positiva, uma vez que a autora acredita que há uma "trança" constante entre gerações, que mantem e leva adiante a agenda feminista. Sempre haverá conquistas e retrocessos. "La libertad, el camino a la libertad de las mujeres y su agenda es diáfana y comprensible” (2016, p. 201)

\section{Metodologia}

Adotou-se a perspectiva de pesquisa qualitativa, do tipo exploratória. O método utilizado foi o de análise de conteúdo, abordando a técnica temática-categorial. Segundo Minayo (2001, p. 74), uma das funções da técnica de análise de conteúdo é a "descoberta do que está por trás dos conteúdos manifestos, indo além das aparências do que está sendo comunicado". O objeto de estudo foi constituído por três fontes escolhidas para análise. A primeira fonte foi constituída pela fundamentação teórica do feminismo na bibliografia adotada. A segunda foi formada pelos grupos posicionados a favor do movimento feminista nas redes sociais. A terceira foi composta pelos grupos posicionados contra o movimento feminista nas redes sociais.

A perspectiva qualitativa apresenta o caráter exploratório ideal que caracterizou a presente pesquisa. Minayo (2001, p. 22) indica que "a abordagem qualitativa aprofunda-se no mundo dos significados das ações e relações humanas". As categorias foram selecionadas a partir dos conteúdos abordados pelos espaços virtuais antifeministas e que são agenda dos movimentos feministas e por isso são contestados ou rebatidos por antifeministas na internet. Ou seja, procuramos os assuntos mais combatidos pelas antifeministas. São eles: igualdade de gênero, aborto, maternidade, empoderamento feminino, e feminicídio. As categorias possibilitaram a comparação entre posições ideológicas de cada um dos grupos escolhidos para análise.

Na tentativa de compreender a resistência ao feminismo pelas mulheres, a pesquisa buscou também estabelecer um diálogo interdisciplinar entre a Comunicação, aqui contida nas redes sociais, e as teorias feminista compreendidas nas Ciências Sociais.

A bibliografia selecionada na pesquisa foi de suma importância para uma melhor aproximação do amplo universo de discussão do movimento feminista, e, também, para que o pesquisador se integrasse do vocabulário e termos técnicos dos movimentos feministas. A partir da leitura dos livros indicados, foi possível analisar os discursos antifeministas a partir do olhar feminista e entender esses processos de forma mais clara. 
O processo de pesquisa foi dividido em 5 fases, sendo elas o levantamento bibliográfico; a busca e mapeamento de sites, blogs, canais do Youtube e páginas no facebook antifeministas; a pré-análise do material selecionado; a exploração do material; o tratamento dos resultados obtidos e a interpretação.

Na etapa de busca e mapeamento de sites, blogs e páginas no facebook antifeministas uma das dificuldades encontradas refere-se à retirada do ar de algumas páginas do Facebook pré selecionadas. Ao revisitar essas páginas para realizar um olhar mais detalhado, elas já não estavam mais disponíveis, o que levava a novas buscas. A saída encontrada foi salvar como arquivos em PDF os conteúdos que interessavam à pesquisa, para evitar o retrabalho e novas buscas de conteúdos para a análise.

Durante a pré-análise foram identificadas e selecionadas as categorias, a partir dos assuntos mais discutidos e combatidos pelos sites e páginas da internet e que são pauta feminista. "É a fase de organização propriamente dita. Corresponde a um período de intuições, mas tem por objetivo tornar operacionais e sistematizar as ideias iniciais, de maneira a conduzir um esquema preciso do desenvolvimento das operações sucessivas, num plano de análise" (BARDIN, 2011, p. 125).

Durante a exploração do material, foram selecionados os blogs, páginas no Facebook e canais no Youtube mapeados, tanto do viés feminista quanto do antifeminista, para realizar a comparação dos dados coletados e dos discursos disseminados, conforme orientado por Bardin (2011, p. 131):

Se as diferentes operações da pré-análise forem convenientemente concluídas, a fase de análise propriamente dita não é mais do que a aplicação sistemática das decisões tomadas. Quer se trate de procedimentos aplicados manualmente ou de operações efetuadas por computador, o decorrer do programa completa-se mecanicamente.

$\mathrm{Na}$ fase de tratamento dos dados coletados, foram analisadas as postagens, vídeos e comentários selecionados pelo pesquisador na fase de exploração do material, com a intenção de comparar o discurso antifeminista com o discurso feminista. Através da comparação das páginas feministas e antifeministas, pudemos analisar o alcance das vozes de cada movimento. 


\section{Resultados e discussão}

Os sites, blogs, páginas do Facebook e canais do Youtube antifeministas mapeados demonstraram, tanto na frequência de postagens de seu conteúdo, quanto na quantidade de curtidas e comentários, uma força muito menor em relação as páginas de conteúdo feminista no espaço virtual. Os exemplos abaixo são um demonstrativo dos acessos, por exemplo podese observar que a página Mulheres contra o Feminismo no período da pesquisa contava com 47.747 curtidas e 47.251 seguidores, enquanto que a página Feminismo Sem Demagogia tinha 1.075.623 curtidas e 1.061.045 seguidores.

\begin{tabular}{|c|c|}
\hline Páginas Antifeministas & Páginas Feministas \\
\hline $\begin{array}{l}\text { DIGA NĂO AS DROGAS } \\
\text { DIGA NĂO AO FEMINISMO } \\
\text { Mulheres contra O } \\
\text { feminismo } \\
\text { (1) MulheresContraofeminis } \\
\text { mo } 47.747 \text { pessoas curtiram isso } \\
\text { ה } 47.251 \text { pessoas estão seguindo isso }\end{array}$ & $\begin{array}{l}\text { Feminismo Sem } \\
\text { Demagogia - } \\
\text { Original } \\
1.075 .623 \text { pessoas curtiram isso } \\
\text { ה } 1.061 .045 \text { pessoss estāo seguindo isso }\end{array}$ \\
\hline
\end{tabular}




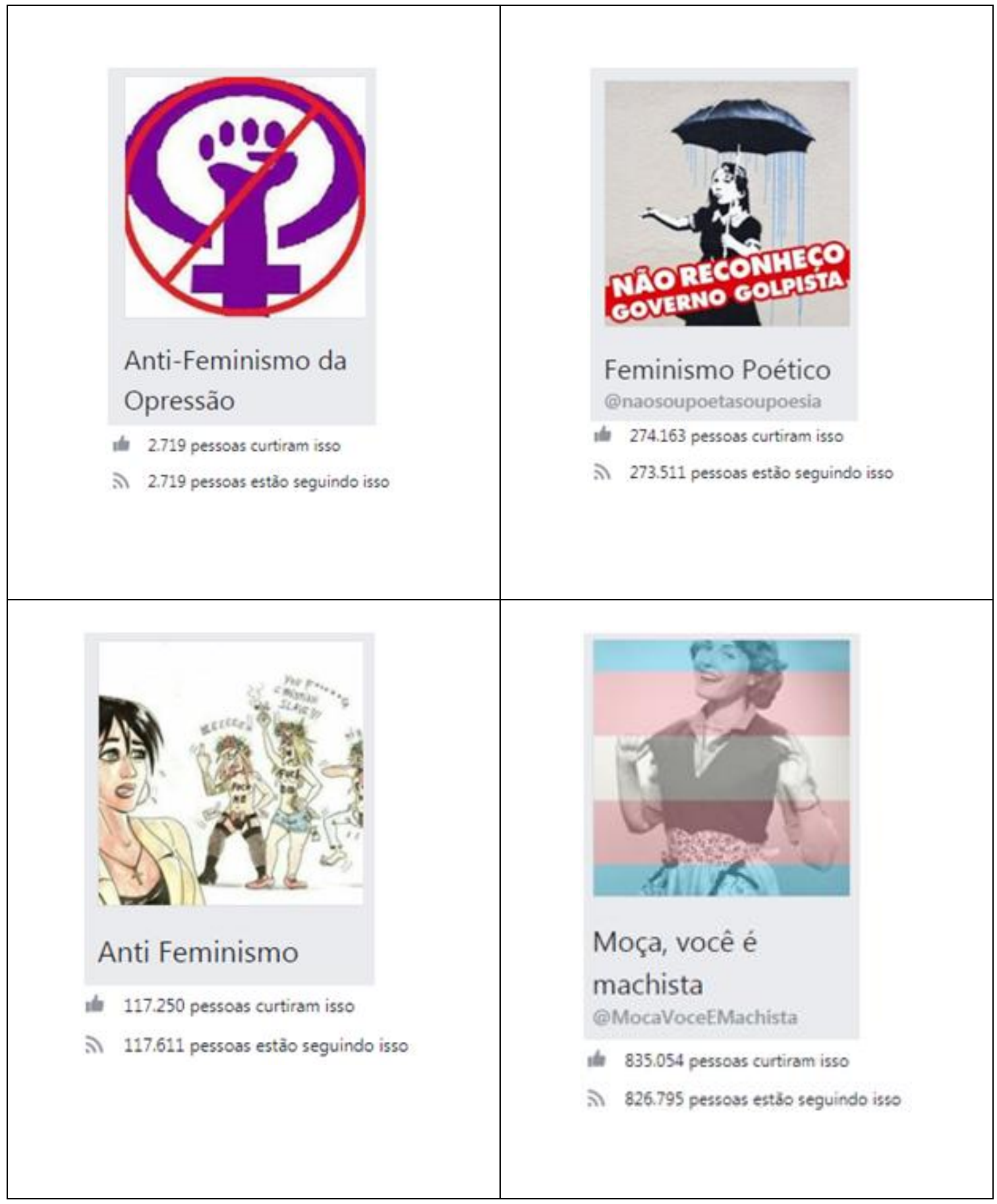

Além disso, durante a etapa de busca e mapeamento da pesquisa, as páginas antifeministas no Facebook não conseguiam se manter no ar por muito tempo sem serem atacadas e posteriormente derrubadas, geralmente por ativistas feministas que contestavam suas postagens, dificultando o processo de pesquisa, pois o recolhimento de dados tinha que ser refeito. Seguem alguns exemplos de páginas que foram excluídas: 
- Fora Feminismo

- O Retrógrado

- Anti-feminismo

Durante esta fase da pesquisa foi possível observar que os discursos antifeministas no espaço virtual se baseavam em um objetivo: deslegitimar as conquistas feministas das mulheres, tornando o movimento obsoleto. Mirla Cisne refuta esta banalização do movimento feminista ao afirmar que

“a importância da apropriação de si está, portanto, na percepção da mulher como sujeito de sua própria vida, o que necessariamente associa-se à superação da ideologia de naturalização do sexo. Afinal, como pensar em uma consciência coletiva voltada para a transformação social se individualmente uma mulher encontra-se alienada de si, sem autonomia sobre sua vida e restringida a cuidar dos outros em detrimento de si?" (CISNE, 2016, p.177).

A partir de falas como a da administradora Léia Sampaio, que comanda a página antifeminista mais ativa no momento, "Movimento Mulheres contra o Feminismo", pudemos notar este discurso de banalização do feminismo: Quero mostrar à sociedade que para uma mulher lutar por seus direitos ela não precisa ser feminista” (REVISTA ISTO É, 2014)

Também é possível notar este tipo de discurso na entrevista de Silvana Deluque para a revista Isto É, em 2014: "Hoje as mulheres têm seus direitos conquistados e amparos legais para recorrer", diz. Ela acredita que homens e mulheres têm papéis diferentes: “A mulher é a mãe que deve estar presente na vida dos filhos e o homem é o chefe da família”.

Observamos que os conteúdos dos espaços virtuais analisados são orientados a partir da agenda feminista. O que é discutido pelos movimentos feministas são contrapostos nos espaços virtuais antifeministas estudados, ou seja, estes espaços não têm uma agenda própria.

A questão ideológica tem um peso importante nas manifestações contrárias ao feminismo quando este é identificado com a esquerda, o que nos leva a supor que há uma ideia de que ao combater o feminismo se está combatendo a esquerda, o socialismo, ou qualquer discurso que busque igualdade. $\mathrm{O}$ trecho abaixo traz essa ideia:

Como diferenciar uma \#mulhercontraofeminismo e uma \#feminista?

- a mulher contra o feminismo consegue raciocinar, pesar as vantagens e desvantagen, tem valores morais definidos e segue a lógica e por isso se torna conservadora ou liberal (logo, direita). Este tipo de mulher se baseia na lógica. 
- A feminista segue o coletivo, segue uma seita e se demonstra incapaz de enxergar o mundo de verdade e prefere fantasia. Por isso, seguem a esquerda e o mito da igualdade (que estranhamente parece ser selecionada pois feminista foge de trabalho pesado). Este tipo de mulher transborda inveja do homem, relativismo moral e tudo o que for de nojento. Defendem qualquer lixo desde que de esquerda ${ }^{4}$.

Esse tipo de discurso pode, ainda, suscitar sentimentos de misoginia, uma vez que a crítica tem forte sentimento de rejeição quando relaciona a mulher a tudo o que for nojento.

A interpretação da pauta feminista é feita sem um cuidado ou conhecimento do debate sobre os assuntos que criticam; reduzem os temas a comentários superficiais, mas que são de fácil entendimento para população em geral. Deste modo, buscam gerar antipatia aos movimentos feministas, e procuram dificultar a adesão de mulheres, como podemos observar em dois comentários ao vídeo "Por que eu deixei de ser feminista" 5 da youtuber e antifeminista Sara Winter:

só quero respeito e igualdade, isso é feminismo pra mim. não quero treta, só quero que as pessoas entendam o que é o feminismo de verdade (Luna Lovebad).

Luna Lovebad tbm penso assim, me digo feminista, mas $\mathrm{n}$ essas militantes que julgam todas as mulheres, mas uma mulher q qr respeito e igualdade (só observo).

Várias dessas pessoas antifeministas dizem que já participaram do movimento feminista e usam isso para legitimar sua fala e se promover na internet. Abaixo mais um trecho do Vídeo supra citado, da youtuber Sara Winter:

As mulheres mais jovens como eu fui, que têm certos traumas, elas são convencidas por esse tipo de discurso midiático de empoderamento feminino a fazer parte do feminismo, e quando elas entram lá dentro, elas se deparam com idéias horríveis de liberação das drogas, de desconstrução da família, porque a família seria só uma célula patriarcal machista que só serve para subjugar a mulher, assim como a maternidade, se desconstrói o gênero, ou seja, se você não quer ser mulher você não precisa (2:55 a 3:30).

Os sites, páginas do Facebook e vídeos do YouTube analisados pela pesquisa trazem conteúdos de ordem moral e do senso comum. Não identificamos conteúdos acadêmicos para

\footnotetext{
${ }^{4} \mathrm{https} / / /$ mulherescontraofeminismo.wordpress.com/ em 5 de abril, às 15:26.

5 https://www.youtube.com/watch?v=fsPIbPASvh4
} 
fundamentar as ideias postadas, a não ser referência a algumas estudiosas antifeministas, mas sem explorar suas ideias mais detidamente.

Como dito anteriormente, as categorias selecionadas para análise durante a pesquisa foram: feminicídio; empoderamento feminino; igualdade de gênero; aborto; e maternidade, com o objetivo de delimitar a busca da pesquisa para áreas específicas da agenda antifeminista. Nestes temas, pudemos recortar alguns discursos mais recorrentes, como os que seguem e que confrontamos com a perspectiva acadêmica feminista:

\section{Feminicídio:}

De acordo com Meneghel e Portella (2017, p. 3079), "o conceito de femicídio foi utilizado pela primeira vez por Diana Russel em 1976, perante o Tribunal Internacional Sobre Crimes Contra as Mulheres, realizado em Bruxelas, para caracterizar o assassinato de mulheres pelo fato de serem mulheres". Esse conceito busca demonstrar que o assassinato de mulheres por homens é caracterizado por sentimentos de ódio, desprezo, prazer e principalmente pelo sentimento de propriedade.

Russel ancora-se na perspectiva da desigualdade de poder entre homens e mulheres, que confere aos primeiros o senso de entitlement - a crença de que lhes é assegurado o direito de dominação nas relações com as mulheres tanto no âmbito da intimidade quanto na vida pública social - que, por sua vez, autoriza o uso da violência, inclusive a letal, para fazer valer sua vontade sobre elas (MENEGHEL; PORTELLA, 2017, p. 3079).

Antifeministas de algumas das páginas visitadas pela pesquisa, que abordaram o assunto, argumentam que a violência doméstica é igualmente praticada entre homens e mulheres, portanto não há necessidade para uma lei que "privilegie" as mulheres. Segundo o site Mulheres contra o feminismo ${ }^{6}$, a autora americana e ex-professora de filosofia Christina Hoff Sommers é conhecida por sua crítica ao feminismo no final do século 20, e é citada pelas antifeministas, por possuir livros altamente discutidos, como "Who Stole Feminism?: How Women Have Betrayed Women" e "The War Against Boys: How Misguided Feminism Is Harming Our Young Men” onde aborda a desinformação muitas vezes proposital sobre a violência doméstica contra a mulher, a raiva de feministas contra homens, a violência doméstica contra homens e sobre dados manipulados da mídia feminista.

6 https://mulherescontraofeminismo.wordpress.com/2013/04/02/mulheres-cultas-trabalhadoras-ameacadas-porserem-contra-o-feminismo-e-suas-mentiras/ 
A youtuber Sara Winter em seu vídeo "Por que eu deixei de ser Feminista" entra em defesa dos homens, demonstrando a falta de entendimento do significado do termo feminicídio, reduzindo o problema a estatísticas:

O feminicídio é uma lei que diz que o assassinato de uma mulher é pior que o assassinato de um homem, simplesmente por ela ser mulher. São os assassinatos discriminatórios contra uma mulher e eles passam a ser hediondos. Se você for ver uma juíza falando sobre o assunto, eu tenho vontade de chorar, porque elas realmente acreditam que as mulheres são mortas simplesmente por serem mulheres, mas os homens não morrem porque são homens" (00:59 a 1:20).

Quando a gente fala só da violência contra a mulher, a gente ta negando que vivemos em um país que está matando 11,5 vezes mais homens do que mulheres" (4:13 a 4:20).

Entretanto, é importante destacar que "as feministas alegam que o fato de não levar em conta o sexo social da pessoa violenta tem por efeito fazer que todas as violências pareçam equivalentes" (ALEMANY, 2009, 275). Além disso, o feminicídio pode ser considerado como parte dos diferentes mecanismos profundamente arraigados na nossa sociedade e na nossa cultura de perpetuação da dominação masculina (MENEGHEL; PORTELLA, 2017).

\section{Igualdade de Gênero:}

"Se os direitos iguais precisam ser declarados, é porque não existem fora da vontade humana que os declara: a igualdade não é uma realidade empírica, mas pode vir a sê-lo" (VARIKAS, 2009, p. 116).

O discurso disseminado pelo antifeminismo, é o de que o movimento feminista prega o ódio irracional contra indivíduos do sexo masculino, e os culpa por fracassos, problemas e frustrações. Pudemos observar características deste discurso, por exemplo, no blog Spotniks:

O que seria o feminismo de verdade, no meu entendimento? Lutar por direitos e DEVERES iguais, onde somos colocadas em pé de igualdade na execução de tarefas, mas também lembrando que há diferenças naturais entre homens e mulheres e que não há problema algum nisso. Não adianta lutar por igualdade de salários, por exemplo, sem entender que para isso é preciso ter a mesma produtividade. Estou dizendo que mulheres são menos capazes, então? NÃO! É claro que 
não. Mas concordam que, se mulheres sempre ganhassem menos que homens, então as empresas só contratariam mulheres? ${ }^{7}$

Em resposta a essa perspectiva antifeminista, Varikas (2009) destaca que a incorporação das mulheres à ordem política já estabelecida, significa que as mulheres devem se adaptar às normas masculinas e se parecerem com homens. Argumenta ainda, que a demanda: "serem admitidas 'como são', numa organização social que leve em conta suas diferenças em relação aos homens (por exemplo, a maternidade, o cuidado das crianças), reforça o regime de exceção do qual elas são objeto e as condena a uma 'incorporação' específica como mulheres, ou seja, "homens imperfeitos".

\section{Empoderamento feminino:}

Foi possível observar a forte presença de argumentos religiosos e do senso comum no discurso antifeminista expressado nas páginas pesquisadas. O empoderamento feminino é citado como uma utopia, como podemos perceber na fala do blog GuiaMe:

Há dois tipos de mulheres na igreja, aquelas que realmente conseguem responder quem é Deus para elas e quem elas são em Deus. Se você não consegue responder da maneira correta essas duas perguntas, vai haver todo esse problema e desequilíbrio. A mulher querendo tomar o lugar que não é dela, ela vai ser frustrada na educação dos filhos, no relacionamento com marido, no lugar que Deus te colocou. Então essas duas perguntas fazem toda diferença. Muitas vezes o diabo tenta destruir esses relacionamentos, dos pais com os filhos, justamente para destruir essa referência de pai ${ }^{8}$.

Outro exemplo é o Blog Padre Paulo Ricardo, que diz

Deus criou o homem e a mulher em igual dignidade, mas quis que houvesse uma diferença entre os dois sexos. Esta diferença em "ser homem" e "ser mulher" faz com que exista uma complementariedade entre eles. Foram criados por Deus para formarem um conjunto, não um sobrepondo ao outro, mas em perfeita sintonia um com outro. Lutar contra esse projeto, fazendo com que a mulher tente, por todos

\footnotetext{
7 (Renata Barreto, 2017 em:

$<$ https://spotniks.com/6-razoes-pelas-quais-tantas-mulheres-questionam-o-movimentofeminista/>

$\overline{8}<$ https://guiame.com.br/gospel/mundo-cristao/e-uma-visao-diferente-da-que-biblia-traz-dizpastora-sobre-empoderamento-feminino.html > 11/03/2018
} 
os meios, ocupar o lugar do homem é lutar diretamente contra o projeto de Deus, contra a natureza humana"9.

Tais argumentos, baseados em senso comum, vão contra a perspectiva do discurso feminista, como por exemplo o que diz Judith Butler sobre ser mulher, ao afirmar que

o gênero nem sempre se constituiu de maneira coerente ou consistente nos diferentes contextos históricos, e porque o gênero estabelece interseções com modalidades raciais, classistas, étnicas, sexuais e regionais de identidades discursivamente construídas. Resulta que se tornou impossível separar a noção de gênero das interseções políticas e culturais em que invariavelmente ela é produzida e mantida (BUTLER, 2016, p. 21)

\begin{abstract}
Aborto:
"O reconhecimento do direito de dispor do seu corpo foi um grande acontecimento para as mulheres do século XIX, essa reivindicação foi objeto de diversas lutas, perdidas ou parcialmente ganhas.” (DEL RE, 2009, p. 21). O discurso antifeminista refuta um dos argumentos da fala feminista de que o aborto no Brasil é também uma questão de saúde pública, pois enfatiza que é mais importante prevenir a gravidez, do que se livrar de uma gravidez já fecundada. É o que se diz no site Mulheres Contra o Feminismo: "Sinceramente, aborto não é questão de saúde pública. Em uma nação como o Brasil aonde pessoas morrem aos milhares comprovadamente devido à falta de verbas, corrupção e outros fatores é infelizmente comum vermos pessoas internadas em corredores e com falta de suprimentos médicas básicos. Mulheres contra o feminismo se responsabilizam pelo que fazem enquanto feministas sempre serão irresponsáveis e zumbis do estado" ${ }^{\prime 10}$.
\end{abstract}

Ao compararmos o discurso feminista sobre essa questão observa-se a amplitude que ele toma, para além da esfera privada. De acordo com Del Re (2009, p. 21),

Quem possui o poder de controle sobre o corpo feminino: o Estado, as autoridades religiosas, as corporações médicas, o chefe da família (marido ou pai) ou as próprias interessadas? É um ponto decisivo, pois se trata da autonomia das mulheres. Exigindo que estas últimas

\footnotetext{
${ }^{9}<$ https://padrepauloricardo.org/episodios/feminismo-o-maior-inimigo-das-mulheres $>$ $02 / 02 / 2012$

${ }^{10}<$ https://mulherescontraofeminismo.wordpress.com/2017/03/11/aborto-nao-e-questao-desaude-publica-desmascarando-mentiras-feministas-sobre-o-aborto/> 11/03/2017
} 
possam ter o domínio da sua sexualidade [...]. [...] o movimento feminista conferiu uma dimensão política a esta questão [...].

\section{Maternidade:}

“Os slogans das feministas pós-68 - 'teremos as crianças que quisermos, se quisermos' e 'nosso corpo nos pertence'- testemunham a vontade coletiva de que a maternidade dependa da liberdade da decisão de cada mulher" (COLLIN; LABORIE, 2009, p. 135).

O discurso antifeminista homogeneiza as mulheres feministas, disseminando o discurso de que feministas percebem a maternidade como abominável, e se recusam a serem mães.

Vejamos: uma mulher que queira ser mãe e abdica de sua profissão. $\mathrm{O}$ que você acha disso? Novamente, como liberal, eu não tenho que achar nada. A vida não é minha, certo? Para as feministas, no entanto, isso está errado. Ser mãe, abdicar da carreira, cuidar dos filhos e até mesmo ter um certo gosto por roupas mais recatadas é tido como algo abominável. Ora, se o lugar da mulher é ONDE ELA QUISER, ela não poderia ESCOLHER o que quiser? Ou só vale quando for algo que o movimento julgue como certo? ${ }^{11}$

Há um reducionismo da discussão sobre maternidade no discurso antifeminista, e um total desconhecimento do debate no interior dos movimentos feministas sobre essa questão, como é possível observar nas ponderações de Collin e Laborie (2009, p. 133):

Que estatuto atribuir à maternidade? Responder a essa questão envolve uma tensão que atravessa a história dos movimentos feministas, mas também a de numerosas mulheres, que se encontram diante de contradições frequentemente insuperáveis. A maternidade constitui, ao mesmo tempo, uma especificidade valorizada - o poder de dar a vida -, uma função social em nome da qual reivindicar direitos políticos ou direitos sociais, e uma das fontes de opressão. Operadora de divisões, ela estrutura as oposições teóricas das feministas.

As autoras destacam, ainda, que a ideia de maternidade difere historicamente. Era comum entre mulheres aristocratas e burguesas rejeitar a maternidade para poderem viver livres e se dedicarem a sua cultura e seus saberes. Havia um comportamento dominante nessas classes de indiferença à criança. Isso começa a mudar no século XVIII, se tornando uma perspectiva parecida com a de nossos dias. "No amor materno, não há, portanto, a evidência de um

11 https://spotniks.com/6-razoes-pelas-quais-tantas-mulheres-questionam-o-movimento-feminista/> $11 / 07 / 2017$ 
instinto, presente por toda a eternidade na natureza feminina: o que há é uma história" (COLLIN; LABORIE, 2009, p. 134).

A seguir apresentamos um quadro com falas antifeministas relacionadas às categorias selecionadas:

\begin{tabular}{|c|c|}
\hline CATEGORIAS & DISCURSO ANTIFEMINISTA \\
\hline Igualdade de gênero & $\begin{array}{l}\text { "A escritora anti-feminista Esther Vilar, argumenta em seu } \\
\text { livro 'O homem domado' (1971) que ao contrário da retórica } \\
\text { feminista e dos direitos femininos, as mulheres em culturas } \\
\text { industrializadas não são oprimidas, e que ao invés disso } \\
\text { exploram um sistema bem estabelecido de manipulação dos } \\
\text { homens. Nele, ela alega que as mulheres não são oprimidas } \\
\text { pelos homens, mas os controlam em um relacionamento que é } \\
\text { vantajoso à elas mas no qual a maioria dos homens não tomam } \\
\text { ciência, como por exemplo: Atrair homens com sexo usando } \\
\text { estratégias de sedução; Usar o elogio para controlar homens } \\
\text { administrando-o com cuidado; Usar chantagem emocional } \\
\text { como meio de controlar os homens; Uso de amor e romance } \\
\text { como um pretexto para disfarçar suas intenções e motivos } \\
\text { reais." (Mulheres Contra o Feminismo, 02/04/2013) } \\
\text { "Liberdade, respeito, igualdade? Puras mentiras feministas da } \\
\text { ditadura feminista hoje existente no Brasil. O movimento } \\
\text { feminista é uma ditadura que censura e condena quem } \\
\text { discorde delas." (Mulheres Contra o Feminismo, 02/04/2013) }\end{array}$ \\
\hline Empoderamento feminino & $\begin{array}{l}\text { "Como dissidente do feminismo, eu rejeito essa projeção } \\
\text { sexista conspiratória. O feminismo argumenta que a } \\
\text { autoestima das mulheres é sistematicamente atacada por } \\
\text { mensagens da sociedade dizendo que elas são inferiores. Por } \\
\text { isso, estariam condenadas a uma vida de preocupação sobre o } \\
\text { que os outros pensam delas. A fascinação das mulheres por }\end{array}$ \\
\hline
\end{tabular}




\begin{tabular}{|c|c|}
\hline & $\begin{array}{l}\text { espelhos, por exemplo, é interpretada como se a mulher } \\
\text { tivesse incorporado o olhar crítico e negativo da sociedade } \\
\text { machista. Não posso concordar com isso." (Camille Paglia, } \\
\text { entrevista à Folha de São Paulo, 24/04/2015) } \\
\text { "É muito triste que as mulheres que realmente sofrem coisas } \\
\text { na pele, dor e sofrimento, estejam sendo coptadas por esse } \\
\text { discurso hollywoodiano e romântico de independência da } \\
\text { mulher, e no final, elas estão sendo usadas apenas como massa } \\
\text { de manobra para dar continuidade aos planos globalistas de } \\
\text { marxismo cultural" (Comentário anônimo no vídeo "Por que } \\
\text { eu deixei de ser Feminista, do canal Sara Winter) }\end{array}$ \\
\hline Feminicídio & $\begin{array}{l}\text { "O feminicídio nada mais é do que uma lei que coloca um } \\
\text { agravante ao crime cometido contra uma mulher, porque } \\
\text { aparentemente a mulher não é ser humano, ela precisa de um } \\
\text { tratamento especial além do que já está na nossa lei, que na } \\
\text { verdade a nossa constitução diz que somos todos iguais } \\
\text { perante a lei, menos se você for uma mulher, você é melhor se } \\
\text { você for uma mulher." } \\
\text { "Quando a gente fala só da violência contra a mulher, a gente } \\
\text { ta negando que vivemos em um país que está matando } 11,5 \\
\text { vezes mais homens do que mulheres." } \\
\text { "O vilão da história é sempre o homem, se não for a gente não } \\
\text { conversa sobre o assunto, a gente tem que ignorar as } \\
\text { estatísticas que comprovam por exemplo que em } \\
\text { relacionamentos entre lésbicas a violência é maior do que em } \\
\text { relacionamentos heterossexuais. A gente ignora esse número } \\
\text { porque ele não condiz com a nossa agenda feminista." (Thaíz } \\
\text { Azevedo) }\end{array}$ \\
\hline Maternidade & $\begin{array}{l}\text { "A liberação sexual promovida pelos métodos } \\
\text { anticoncepcionais, longe de trazer a sensação de igualdade } \\
\text { entre o homem e mulher, transformou a mulher numa máquina } \\
\text { de prazer, pois agora ela sabe que pode ter uma vida sexual }\end{array}$ \\
\hline
\end{tabular}




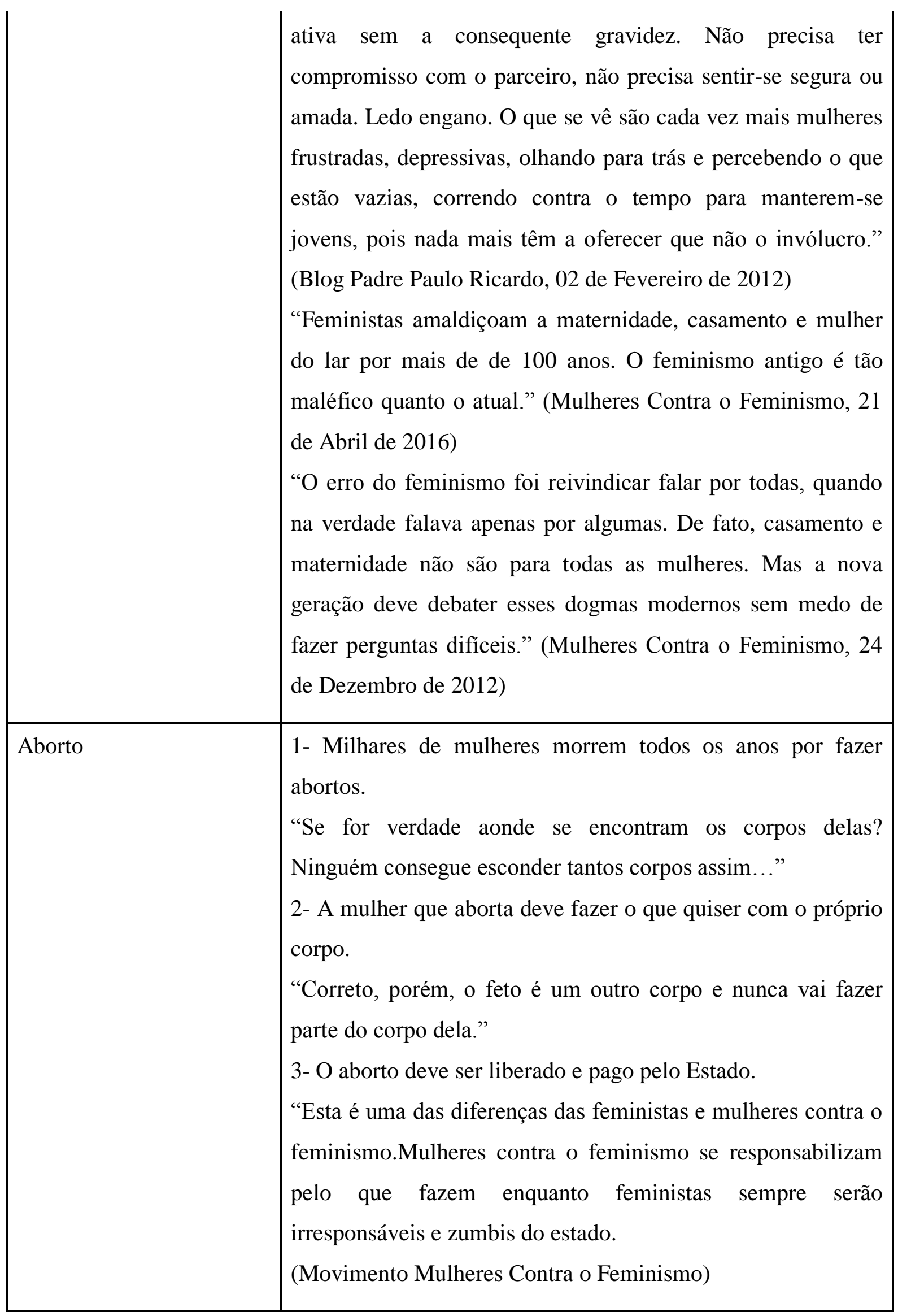




\section{Considerações Finais}

A presente pesquisa procurou deslocar-se até o olhar de pessoas antifeministas, principalmente do sexo feminino, para compreender o que as motiva neste movimento que vai contra o bem-estar e a reivindicação de direitos para elas mesmas e por que existem mulheres que defendem esse discurso ancorado no senso comum, que é tão opressor e machista. Embora as origens do feminismo tenham como características ser intelectual, branco e de classe média, o movimento feminista contemporâneo apresenta um discurso múltiplo, mas com bases comuns. "Envolve diversos movimentos, teorias e filosofias, advogando pela igualdade entre homens e mulheres, além de envolver a campanha pelos direitos das mulheres e seus interesses" (CRUZ e DIAS, 2015, p. 36).

As profissões e locais de trabalho declarados no universo pesquisado no Facebook, nos levaram a supor que o público antifeminista em sua maioria pertence a um padrão social de pessoas de classe média-baixa e média-alta, pois identificamos, por exemplo, donas de salões de beleza, donos de empresas de estética, médicos em hospitais renomados (como Sírio Libanês), professores e auxiliares administrativos ${ }^{12}$. Em geral o público era composto de pessoas com expressão de ideias fundamentalistas que baseiam seus argumentos em discursos do senso comum, religiosos, tradicionalistas, ou discursos políticos de extrema direita. Além disso, foi notória a diferença da intensidade dos argumentos entre as páginas de Facebooks/Blogs, e os argumentos dos comentários do YouTube. Neste último, os comentários eram muito mais livres e fervorosos (com discursos de ódio mais aparentes), por conta do anonimato dos usuários. Diferente do Youtube, nas páginas de Facebook os perfis dos usuários ficam aparentes em seus comentários, sendo assim, qualquer internauta pode ter acesso a muitos de seus dados pessoais (como local de trabalho, fotos, perfil do cônjuge, etc). A partir desses aspectos, pudemos inferir que os usuários do Facebook são mais contidos em seus comentários, evitando evidenciar discursos de ódio. Até porque algumas páginas são passíveis de serem derrubadas devido às denúncias vindas de usuárias (os) e páginas que se opõem à essas ideias, e à maior exposição. Isso é interessante porque demonstra que há uma vigilância crítica de usuários em favor dos direitos das mulheres defendidos pelos movimentos feministas.

Percebemos que a discussão teórica sobre a dificuldade da atual geração de se identificar com a agenda feminista, de não se enxergar como parte de algo mais amplo do que suas

\footnotetext{
${ }^{12}$ Preferimos não colocar imagens destes dados na pesquisa para não expor os perfis destas pessoas.
} 
necessidades e dilemas individuais, trazida por Cacace (2006) e Valcárcel (2016), pode explicar parte desse ativismo digital contrário à pauta de movimentos feministas.

A pesquisa apontou a necessidade de mais estudos para identificar a capacidade de alcance e convencimento desses espaços virtuais antifeministas, uma vez que propagam discursos que mantém o padrão de relações de gênero desiguais, reafirmam ideais de heteronormatividade, enfim, reforçam estereótipos e preconceitos.

Os objetivos do projeto foram alcançados no que diz respeito ao mapeamento e categorização das temáticas abordadas, da análise dos conteúdos e da resposta das perguntas iniciais da pesquisa, como em qual medida os conteúdos produzidos no ciberespaço fazem apologia à misoginia, e qual o perfil do público que acessa esses espaços virtuais antifeministas, além de relacionar a produção antifeminista e seus contrapontos aos fundamentos teóricos feministas.

\section{Referências}

1. ALEMANY, Carme. Violências. In: HIRATA, Helena et al (orgs). Dicionário Crítico do Feminismo. São Paulo: Editora UNESP, 2009. p. 271-276

1. ALVES, Branca Moreira; PITANGUY, Jacqueline. O que é FEMINISMO. São Paulo : Ed. Abril cultural : Brasiliense, 1985.

2. BANDEIRA, Lourdes. Três Décadas de Resistência Feminista contra o Sexismo e a Violência Feminina no Brasil: 1976 a 2006. Sociedade e Estado [online], Brasília, v. 24, n. 2, p. 401-438, maio/ago. 2009.

3. BARDIN, Laurence. Análise de conteúdo. Tradução Luís Antero Reto, Augusto Pinheiro. São Paulo: Edições 70, 2011.

4. BATLIWALA, Srilatha. The Meaning of Women's Empowerment: New Concepts from Action. GERMAIN, Adrienne; CHEN, Lincoln C; SEN, Gita; Harvard School of Public Health. Center for Population and Development Studies \& International Women's Health Coalition. Population policies reconsidered : health, empowerment, and rights. Harvard Center for Population and Development Studies ; New York, N.Y. : International Women's Health Coaliton ; Boston : Distributed by Harvard University Press, Boston, Mass, 1994.

5. BUTLER, Judith. Problemas de gênero. 12a . Ed. Rio de Janeiro: Civilização Brasileira, 2016.

6. CACACE, Marina. Mujeres Jóvenes y feminismo: valores, cultura y comportamientos frente a frente. Madri: Narcea, S.A. de Ediciones, 2006.

7. CASTELLS, Manuel. O poder da identidade. Tradução Klauss Brandini Gerhardt. São Paulo: Paz e Terra S.A., 2001. 
8. CISNE, Mirla. Feminismo e consciência de classe no Brasil. São Paulo: Cortez, 2014.

9. COLLIN, Françoise; LABORIE, Françoise. Maternidade. In: HIRATA, Helena et al (orgs). Dicionário Crítico do Feminismo. São Paulo: Editora UNESP, 2009. p.133-138

10. CRUZ, Maria Helena S, DIAS, Alfrancio Ferreira. Antifeminismo. Revista de Estudos de Cultura [online],| no 01, jan.abr./2015.

11. DEL RE, Alisa. Aborto e contracepção. In: HIRATA, Helena et al (orgs). Dicionário Crítico do Feminismo. São Paulo: Editora UNESP, 2009. p. 21-30

12. FERREIRA, Carolina Branco de Castro. Feminismos web: linhas de ação e maneiras de atuação no debate feminista contemporâneo. Cad. Pagu, Campinas , n. 44, p. 199-228, jun. 2015 .Disponível em <http://www.scielo.br/scielo.php?script=sci_arttext\&pid=S010483332015000100199\&lng=pt\&nrm=iso $>$ acessos em 03 maio 2017. http://dx.doi.org/10.1590/1809-4449201500440199.

13. FOLHA DE SÃO PAULO. Mulher deve ser maternal e parar de culpar o homem, diz Camille Paglia. 24/04/2015. Disponível em: https://www1.folha.uol.com.br/ilustrada/2015/04/1619320-nao-publicar-entrevista-camillepaglia-fronteiras-do-pensamento.shtml

14. GARCIA, Leila Posenato. A magnitude invisível da violência contra a mulher. Epidemiol. Serv. Saúde, Brasília , v. 25, n. 3, p. 451-454, Sept. 2016 . Available from $<$ http://www.scielo.br/scielo.php?script=sci_arttext\&pid=S2237-

96222016000300451\&lng=en\&nrm=iso>. access on 23 Aug. 2018. http://dx.doi.org/10.5123/s1679-49742016000300001.

15. HARVEY, David. Condição pós-moderna: uma pesquisa sobre as Origens da Mudança Cultural. 4ª Edição. Edições Loyola, São Paulo, 1994.

16. KIMURA, Herbert; TEIXEIRA, Maria Luisa Mendes; GODOY, Arilda Schmidt. Redes sociais, valores e competências: simulação de conexões. Rev. adm. empres., São Paulo, v. 46, n. 3, p. 42-58, set. 2006. Disponível em $<$ http://www.scielo.br/scielo.php?script=sci_arttext\&pid=S0034-

75902006000300005\&lng=pt\&nrm=iso>. acessos em 02 maio 2017. http://dx.doi.org/10.1590/S0034-75902006000300005.

17. LANGNER, A.; ZULIANI, C. S. ; MENDONCA, F. . O Movimento Feminista e o Ativismo Digital: conquistas e expansão decorrentes do uso das plataformas online. In: 3o Congresso Internacional de Direito e Contemporaneidade: Mídias e Direitos na Sociedade em Rede e V Congresso Iberoamericano de Investigadores e Docentes de Direito e Informática, 2015, Santa Maria. 3o Congresso Internacional de Direito e Contemporaneidade: Mídias e Direitos na Sociedade em Rede e V Congresso Iberoamericano de Investigadores e Docentes de Direito e Informática. Santa Maria: Universidade Federal de Santa Maria, 2015. Disponível em <http://coral.ufsm.br/congressodireito/anais/2015/3-12.pdf> acessos em 02 maio 2017.

18. LEVY, Pierre. Cibercultura. São Paulo. Editora 34, 1999. 
19. MEDINA, Marianna Michelle. Configurações do discurso machista na internet: O blog Testosterona e os embates ideológicos na era digital.Jangada: crítica, literatura, artes, [S.1.], n. 2, p. 57-74, jan. 2014. ISSN 2317-4722. Disponível em: <http://www.brazilianstudies.com/ojs/index.php/jangada/article/view/5>. Acesso em: 04 maio 2017.

20. MENEGHEL, Stela Nazareth; PORTELLA, Ana Paula. Feminicídios: conceitos, tipos e cenários. Ciência \& Saúde Coletiva, 22(9):3077-3086, 2017. Disponível em: http://www.scielo.br/pdf/csc/v22n9/1413-8123-csc-22-09-3077.pdf

21. MINAYO, Maria Cecília de Souza (org.). Pesquisa Social. Teoria, método e criatividade. 18 ed. Petrópolis: Vozes, 2001.

22. PARCERIAS. Princípios de Empoderamento das Mulheres. Disponível em <http://www.onumulheres.org.br/referencias/principios-de-empoderamento-das-mulheres/> Documento sem data de publicação. Acesso em 5 mai. 2017.

23. REVISTA ÉPOCA. Entrevista de Camille Paglia: "O Feminismo não é honesto com as mulheres". 08, Março de 2012. Disponível em: $<\underline{\text { http://revistaepoca.globo.com/vida/noticia/2012/03/camille-paglia-o-feminismo-nao-e- }}$ honesto-com-mulheres.html> Acesso em: 11, Julho de 2018.

24. REVISTA ISTO É. O Movimento das Anti-feministas. 08/08/2014. Disponível em: https://istoe.com.br/376787_O+MOVIMENTO+DAS+ANTI+FEMINISTAS/

25. RODRIGUES, Alexsandra Gato; GADENZ, Danielli; LA RUE, Letícia Almeida de. Feminismo.com: O Movimento Feminista na Sociedade em Rede. Derecho y Cambio Social. Lima-Peru, n. 36, ano XI, 2014. Disponível em: <http://www.derechoycambiosocial.com/revista036/FEMINISMO.COM.pdf>. Acesso em: 03 Mai. 2017.

26. SCHMIDT, Rita Terezinha. Refutações ao feminismo: (des) compassos da cultura letrada brasileira. Rev. Estud. Fem., Florianópolis , v. 14, n. 3, p. 765-799, dez. 2006 . Disponível em <http://www.scielo.br/scielo.php?script=sci_arttext\&pid=S0104026X2006000300011\&lng=pt\&nrm=iso>. acessos em 02 maio 2017. http://dx.doi.org/10.1590/S0104-026X2006000300011.

27. SOUSA, Thais; FRANCHINI; Estevão; NASCIMENTO, Paulo. Os Memes como Representações Políticas nas Redes Sociais: Uma Análise de Forma e Conteúdo na Produção de Sentido e Construção de Identificação com Grupos e Movimentos. Faculdades Integradas de Bauru [online], São Paulo. 2016.

28. VALCÁRCEL Amelia. Feminismo en el Mundo Global. 5ª Ed. Madrid: Ediciones Cátedra, 2016.

29. VARIKAS, Eleni. Igualdade. In: HIRATA, Helena et al (orgs). Dicionário Crítico do Feminismo. São Paulo: Editora UNESP, 2009. p. 116-122

30. VELLOSO, Ricardo Viana. O ciberespaço como ágora eletrônica na sociedade contemporânea. Ci. Inf., Brasília , v. 37, n. 2, p. 103-109, ago. 2008 . Disponível em 
<http://www.scielo.br/scielo.php?script=sci_arttext\&pid=S0100$19652008000200008 \& \operatorname{lng}=$ pt\&nrm=iso $>$ acessos em http://dx.doi.org/10.1590/S0100-19652008000200008.

$04 \quad$ maio 2017.

\section{Lista de sites, Blogs, Facebook, Youtube citados:}

FEMINICÍDIO, SÓ A MULHER É A VÍTIMA. O Retrógrado, 31, Agosto de 2017. Disponível em: <http://www.oretrogrado.com.br/2017/08/31/feminicidio-so-a-mulher-e-avitima/> Acesso em: 15, Fevereiro de 2018.

FEMINISMO, O MAIOR INIMIGO DAS MULHERES. Blog Padre Paulo Ricardo, 02, Fevereiro de 2012. Disponível em: <https://padrepauloricardo.org/episodios/feminismo-omaior-inimigo-das-mulheres $>$ Acesso em : 15, Fevereiro de 2018.

GAROTO OPRESSOR 2.0. Página do Facebook. 24, Junho de 2017. Disponível em $:<$ https://www.facebook.com/GarotoOpressor2.0/videos/vb.158567181298521/247090839112

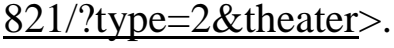

O MOVIMENTO DAS ANTI FEMINISTAS. Isto É, 08, Agosto de 2014. Disponível em: <https://istoe.com.br/376787_O+MOVIMENTO+DAS+ANTI+FEMINISTAS/>.

Acesso em: 09, Julho de 2018.

POR QUE EU DEIXEI DE SER FEMINISTA. Sara Winter, 12, Fevereiro de 2017. Disponível em: <https://www.youtube.com/watch?v=fsPIbPASvh4> Acesso em: 10, Abril de 2018.

FEMINICÍDIO. Mulheres Contra o Feminismo, Thaís Azevedo, 07, Abril de 2018. Disponível em:

<https://www.facebook.com/MulheresContraoFeminismo/videos/1740639472696081/>

Acesso em: 10, Abril de 2018.

"É UMA VISÃO DIFERENTE DA QUE A BÍBLIA TRAZ", DIZ PASTORA SOBRE EMPODERAMENTO FEMININO. Guia Me, 11, Março de 2018. Disponível em: $<$ https://guiame.com.br/gospel/mundo-cristao/e-uma-visao-diferente-da-que-biblia-traz-dizpastora-sobre-empoderamento-feminino.html> Acesso em: 08, Julho de 2018.

ABORTO NÃO É UMA QUESTÃO DE SAÚDE PÚBLICA: DESMASCARANDO MENTIRAS FEMINISTAS SOBRE ABORTO. Mulheres contra o Feminismo, 11, Março de 2017. Disponível em :

<https://mulherescontraofeminismo.wordpress.com/2017/03/11/aborto-nao-e-questao-desaude-publica-desmascarando-mentiras-feministas-sobre-o-aborto/> Acesso em: 12, Abril de 2018.

6 RAZÕES PELAS QUAIS TANTAS MULHERES QUESTIONAM O MOVIMENTO FEMINISTA. Renata Barreto, Spotniks, 11, Julho de 2017. Disponível em: <https://spotniks.com/6-razoes-pelas-quais-tantas-mulheres-questionam-o-movimentofeminista/> Acesso em: 11, Julho de 2018. 
MULHERES CULTAS E TRABALHADORAS AMEAÇADAS DE SEREM CONTRA O FEMINISMO E SUAS MENTIRAS. Mulheres contra o Feminismo. 02, Abril de 2013. Disponível em: <https://mulherescontraofeminismo.wordpress.com/2013/04/02/mulherescultas-trabalhadoras-ameacadas-por-serem-contra-o-feminismo-e-suas-mentiras/> Acesso em: 11, Julho de 2018. 